sciendo

\title{
Critical Notice \\ Baier and Cottingham on the meaning of life
}

Thaddeus Metz

University of the Witwatersrand

Disputatio Vol. 1, No. 19

November 2005

DOI: $10.2478 /$ disp-2005-0011

ISSN: 0873-626X 


\title{
Critical notice
}

\section{Baier and Cottingham on the meaning of life}

\author{
Thaddeus Metz \\ University of the Witwatersrand
}

\begin{abstract}
I examine two recent books by analytic philosophers that address the underexplored topic of whether the meaning of life depends on the existence of a supernatural realm including God and a soul. John Cottingham's On the Meaning of Life defends a supernaturalist conception of life's meaning, whereas Kurt Baier's Problems of Life and Death defends the opposite, naturalist perspective. I show that their respective arguments are worth serious consideration, indicate some potential weaknesses in them, and suggest some other argumentative strategies that those interested in this fascinating topic might pursue elsewhere in more depth.
\end{abstract}

In this article I discuss two books by important analytic philosophers that explore the neglected topic of what makes a person's life meaningful. A central part of a book by Kurt Baier takes up this topic, ${ }^{1}$ and an entire book by John Cottingham does so. ${ }^{2}$ Although Baier's book explores topics such as religion and morality apart from their bearing on life's meaning, I discuss his book solely in light of what it says on this latter issue. I do this not only because this will facilitate comparison and contrast with Cottingham, but also because it is largely on meaning that Baier has something new to say (though I also recommend his discussion of the deontological do/allow distinction).

Beyond subject matter, the two books share an additional commonality, namely, they both address an audience larger than just academic philosophers. Baier's book is composed of Prometheus

\footnotetext{
${ }^{1}$ Baier 1997.

${ }^{2}$ Cottingham 2003.
}

Disputatio, Vol. I, No. 19, November 2005 
Lectures that were delivered at the University of Buffalo, and is aimed at educated readers who might not know, say, the fundamentals of a humanist worldview. Cottingham's book is part of Routledge's Thinking in Action series, which aims to bring philosophy out of the academy and into the minds of the public. His book is elegantly written, with illuminating metaphors, striking images and moving turns of phrase. The two books cast a wide net, one that does not fail to snare specialists; a reader of this journal, too, will find something of use in these books despite their orientation toward a general audience.

The most striking dissimilarity between the two books concerns the theses defended. In value theory, Baier is as well known for his atheism as Cottingham is for his theism, and these views inform their respective accounts of meaning in life. Baier denies that God and a soul are necessary for meaning in life, whereas Cottingham affirms that they are. In what follows, I bring out this difference between the two authors and suggest avenues of research for those who wish to continue the debate between naturalism and supernaturalism.

Baier's book takes the same basic positions on life's meaning first expressed nearly fifty years ago in his widely read inaugural lecture. ${ }^{3}$ However, the book typically defends these positions with different arguments or in more depth, and it takes up some new issues unaddressed in previous work. For instance, the book works to articulate the sense of the question of life's meaning. Baier is relatively unique among theorists for clearly distinguishing the question of what (if anything) would make a life meaningful from other normative questions such as: whether a life is happy or rewarding; what it is to act in a morally right way; whether a life is good; and whether a life is worth living. Too often, I think, people are wrongly inclined to identify the question of life's meaning with one of these other questions. It is an open question whether a meaningful life is a happy one (sacrificing one's free time to care for a sick relative), a moral one (abandoning others to realise one's substantial artistic talents), a good one (a soldier grotesquely disfigured as a result of justly fighting in other-defence), or one worth living (perhaps the same case). Any relationship between meaning and these other evaluative categories is likely a substantive or argumentative matter, not a conceptual or definitional one.

${ }^{3}$ Baier 1957. 
If meaning is a logically distinct category, as Baier maintains, then one might like some elaboration on what it concerns. Baier admirably takes up this challenge. He notes that when we ask what (if anything) makes life meaningful we might be asking what could make human life in general (the race or species) meaningful, on the one hand, or we could be enquiring about what could make a particular human life meaningful, on the other. Baier rightly points out that it is consistent to hold one to be meaningful without holding the other to be, but that thinkers often maintain that the meaning of one has substantive implications for the meaning of the other. Baier usually addresses both simultaneously, but I here focus solely on the way he answers the question of what makes an individual's life meaningful. Most of us care about whether the human species is significant, if at all, only insofar as it bears on the question of whether and how our own lives as individuals can be significant.

Baier draws an additional, more novel distinction between two different questions we might be asking with the question of life's meaning. He says that could be enquiring as to whether an individual's life has a meaning or whether it has meaning. To ask whether a person's existence has a meaning, for Baier, is to ask this: whether its essential character is so good as to largely make up for the bads suffered. Enquiring about $a$ meaning, again, involves asking whether there is something substantially positive about what a human's life basically amounts to. Baier says that to ask such a question permits of an explicit answer with respect to what the meaning is, with three traditional answers being: to play a role in God's plan; to exhibit aesthetic qualities such as creativity, beauty, and narrative coherence in one's life; and to act in this world so as to receive eternal bliss in the next one.

In contrast, Baier says that asking whether a life has meaning (but not $a$ meaning) does not call for an answer specifying what the meaning is, but rather one indicating 'on account of what it is meaningful... what we want to know is not precisely what it means... what we want to know is its ground, what makes it meaningful' (1997, 57). We seek the ground of meaning rather than its content in cases where something is meaningful to someone, i.e., in situations where a person perceives or judges something as meaningful.

At times, something (for instance, a person's relationship to someone, or her letter of condolence to us, or her embrace of a former lover) has meaning or is meaningful to or for us or something else. In such a case, a 
person's recognition of the meaningfulness of something in this sense does not depend on her knowing an answer to what that meaning is (Baier 1997, 57).

Baier does not sketch standard answers to the question of in virtue of what life has meaning to someone, but merely presents his own. He maintains that a life has meaning (or we deem life to be meaningful) in virtue of its being valuable or significant, where a life is valuable insofar as it helps others and significant insofar as it influences them (not necessarily in desirable ways).

Although thought provoking, I find the distinction between having $a$ meaning and having meaning obscure. I can grasp one way to draw a clear distinction with the terms that Baier is using. In normative ethical theory, one answers the question of what the moral thing to do is by claiming that it is, e.g., the act with the best consequences or one with the proper maxim, and in meta-ethical theory, one answers the question of in virtue of what the act is moral by saying that, e.g., an act's morality is identical to a supernatural property such as the object of God's will or to some natural property. This distinction in moral theory is familiar and readily grasped, but it does not parallel the distinction that Baier is trying to draw in meaning theory. When asking in virtue of what life has meaning, for Baier, we are not asking about which sort of metaphysical properties constitute the meaning; rather, we are still on the normative level in some way, one that supposedly does not involve asking for a specification of the meaning but rather its 'ground.'

I submit that the most plausible understanding of Baier's two questions about meaning ultimately collapses them into a single question. Asking whether life has a meaning is supposed to ask about the 'essential character' of a life. But the 'essential character' of an individual's life, for Baier, need not be something invariable or universally shared. If exhibiting aesthetic qualities and acting so as to gain entrance to Heaven can count as the 'essential character' of a person's life, then one would think that this could also be constituted by being valuable and significant (influencing others, particularly in helpful ways), ways that life may have meaning for Baier. Furthermore, asking whether life has a meaning is supposed to enquire about whether the essential character of an individual's life is positive in a way that could mitigate the negative. But virtually whenever we ask whether our lives are meaningful we are seeking something positive, and so a quest 
for the positive would reasonably characterise the question of whether life has meaning as well.

In light of these remarks, one sees that answers to one question are readily construed as answers to the other. For instance, when asking whether life has meaning and so seeking the 'ground' of what is (or should be) meaningful to people, one could conceivably answer that life has meaning in virtue of its aesthetic properties or its playing a role in God's plan, alleged answers to the question of whether life has a meaning. And, conversely, the claim that a person has done a lot to help others in the course of her life seems to be a fair answer to the question of what the meaning of a life is, what its positive essential character is.

In contrast to Baier, I think that when people ask what, if anything, makes an individual's life meaningful they are generally asking something to the effect of what it might be about life that is worthy of great pride or admiration, or how one can make one's existence estimable apart from making it well off or fulfilling moral obligations. ${ }^{4}$ I think such a question is clearer than Baier's formulations, and is closer to what most reflective people have in mind. Plus, such a question unifies Baier's discussion, admitting of all the theoretical answers he canvasses: fulfilling God's purpose, living an aesthetic life, living at a higher level in Heaven than one did on earth, having a major influence on others, and helping them.

We need not have a terribly specific understanding of the sense of the question of life's meaning in order to have substantive, theoretical debate about the proper way to answer it (any more than we do in morality). We merely need to be able to distinguish the question of what constitutes meaningfulness from questions regarding happiness, rightness, beauty and other, logically distinct values. Therefore, in the rest of this article, I set aside Baier's distinction between having meaning and having a meaning, and instead rely on the reader's intuitive sense of the question of life's meaning (which, I hope, lines up with my proposal above).

So far, I have discussed the way Baier deals with linguistic or conceptual analyses of the question of life's meaning. Now I turn to his substantive answer to the question. Baier centrally maintains that life is meaningful

${ }^{4}$ Metz 2001; Metz 2002, 801-804. 
insofar as it has a large impact on people's lives (significance) or substantially helps them (value). ${ }^{5}$ This is obviously a naturalist conception, for a life can have an impact on others and benefit them independent of the existence of either God or a soul. Furthermore, it is an account denying that immortality (whether embodied or not) is necessary for meaning in life.

One way to question Baier's account of meaning in life would be to point to additional naturalist sources of meaning, e.g., I and others such as Robert Nozick and Alan Gewirth maintain that one's life can have meaning insofar as one makes a substantial scientific discovery or a beautiful and deep artwork, ${ }^{6}$ neither of which necessarily count as 'valuable' or 'significant' as Baier uses these terms. However, I instead focus on the way a supernaturalist might respond to Baier. What I do first is question Baier's arguments for thinking that no supernatural realm is necessary for meaning in life. Then, I bring out why Cottingham would disagree with Baier.

Baier has two central arguments for thinking that death, an absence of an immortal soul, would not undercut meaning in life. The two arguments could equally entail that God's non-existence would not undercut meaning, but, since Baier does not tend to mention God, I do not highlight this implication. First, then, Baier argues that when ascertaining whether a life is meaningful, it is appropriate to compare it to the average of its kind. Just as a good student is one whose work shows a greater comprehension than the average student's, so a meaningful life is one that is more valuable and significant than average. Since all lives end, the fact that one's own life ends makes it no worse on average than others, and hence does not lessen its meaning.

One problem with this argument is that it seems to have an overly narrow notion of how to evaluate something's worth. A particular childbirth might go a bit easier compared to the average childbirth, and hence on Baier's view count as 'good.' However, since the labour still involves enormous amounts of pain, it surely counts as (intrinsically) 'bad' in a relevant and important respect. By analogy, even if

\footnotetext{
${ }^{5}$ Baier does not really answer his question of whether life has a meaning, merely sketching the way others have done so, and hence this is his answer to his question of whether life has meaning.

${ }^{6}$ Nozick 1981; Gewirth 1998; Metz 2003.
} 
one's life is significant and valuable relative to average lives, it and all other lives could be lacking meaning insofar as they come to an end.

In fairness, Baier acknowledges that it is possible to evaluate a life's meaning apart from how much value and significance it has relative to average lives. He says that even if one life were much more valuable and significant than others, it would be an open question whether we should call this life 'meaningful on balance.' Here, Baier contends that the right standard to use is something like the maximum amount of value and significance a person's life could have on earth. Those who were to come toward the highest end of the scale would have a meaningful life on balance.

This account of meaning in life on the whole faces a dilemma. On the one hand, it is arbitrary as it stands. There seems to be no principled reason to pick a location (the earth) by which to evaluate a life. What if, in the future, human beings lived much longer, and hence helped more people for a longer time, by living in space? Such a possibility seems prima facie relevant. On the other hand, if Baier modifies his view to take into account such extraterrestrial possibilities, then it might follow that no human lives up to now have been meaningful. If we could in fact live much longer in space, then no earthly life would approximate the maximum amount of value and significance possible for us, and hence no earthly life would be meaningful on balance — something that seems implausible and, in any event, goes against the thrust of what Baier wants to claim. I submit that theorists should make the effort to sort out this puzzle in future work.

Baier's second argument for thinking that immortality is not necessary for meaning starts from the point that, assuming we are in fact mortal, there is nothing we can do to change that fact. Underlying Baier's discussion is the premise that if one cannot change a state of affairs, that state of affairs cannot affect the disvalue of one's life. People often suggest something like this when they tell others not to get upset about aspects of life that they cannot control. Now, if a state of affairs can be bad for us only if we can change it in some way, and if we cannot change whether we die, then our deaths cannot be bad for us. Hence, again, for Baier death as such does not detract from the meaning of our lives.

However, counterexamples to the key premise abound. Here is one: supposing I cannot change the fact that my wife will die before me, her death will still be bad for me (and only a Zen master could think of claiming otherwise). Furthermore, imagine that we experi- 
enced a certain pleasure that we could not alter. It would surely be good for us despite our inability to control it; by analogy, something could be bad for us even though we could not alter it. On a more principled level, a state of affairs might have dis/value for a person if she is capable of non-volitional judgment-sensitive attitudes with respect to it. A person's life is not merely the sum of actions, but also other reactions not involving the will that can be reasons-responsive. Even if one's volitions cannot alter a certain state of affairs, it might nonetheless be good or bad for one so long as one can have certain conative, cognitive, affective, emotional or attitudinal responses to it.

Baier might be correct that death is compatible with meaning in life, but I have contended that his reasons for thinking so are unconvincing as they stand. I suspect that a stronger rationale for his view would point to instances of what he calls 'value' that seem to confer meaning on life even if we lack an immortal soul. As Anthony Flew remarked long ago, it would be odd for a doctor not to take an interest in curing people for the Keynesian reason that in the long run we are all dead. ${ }^{7}$ One might go farther, as Martha Nussbaum has in more recent work, and note that if we were immortal, then saving others would not be very important at all $^{8}$; vulnerability seems necessary for help to matter. Insofar as we are convinced that helping others can be a central source of meaning in our lives, we should be disinclined to think that an immortal soul is necessary for such meaning. However, let us now see why Cottingham would reject this line of reasoning.

Like Baier, Cottingham believes that acting morally, which of course includes helping others, is necessary for meaning in life. Unlike Baier, Cottingham denies that moral action is sufficient to make a life significant. In Cottingham's book I count two basic reasons for thinking that something more — something beyond — is also necessary for meaning in life.

First, Cottingham maintains that success in one's projects is necessary for them to confer significance on one's life. Meaning is particularly upset by failure to achieve one's moral ends, where such ends might include helping others or receiving what is deserved. Only an allpowerful, all-good and all-knowing being could order the world so that,

\footnotetext{
${ }^{7}$ Flew 1966, 105.

${ }^{8}$ Nussbaum 1989.
} 
presumably after our bodily deaths, our ends are realised or at least our losses are redeemed. With respect to Baier, I presume Cottingham would argue that, even if we occasionally succeed in helping others in this world, much more often our moral ends go unfulfilled, requiring another world for meaning to come from their fulfilment.

Second, Cottingham argues that moral principles must be grounded in an absolute order for our lives to obtain significance by acting in accordance with them. Neither nihilism, relativism nor even a species-wide morality would be enough to confer meaning, for Cottingham. Instead, only moral norms that are applicable to all agents in all places and at all times, and that hence must spring from a spiritual ground of the physical universe, would be enough to make our lives important when conforming to them. Regarding Baier, then, Cottingham would contend that the only sort of morality that matters is one that is God-based.

In addition to arguing that the existence of God and a soul partly constitutes what it is for a life essentially to be significant, Cottingham contends that belief in their existence, or rather acting as though they exist, is necessary for us to be able to obtain significance. As I understand it, this latter claim is not about the content of a meaningful life, but rather about what to do so that one's life is enriched with this content. Cottingham's claim, in a nutshell, is that we will not be motivated to pursue challenging moral projects if we lack faith that we can eventually partake of a spiritual realm.

(I)f the ultimate nature of reality contains no bias towards the good as opposed to the vicious, if there is nothing to support the hope that the good will ultimately triumph, if essentially we are on our own, with no particular reason to think that our pursuit of the good is any more than a temporary fragile disposition possessed by a percentage (perhaps a minority) of a certain class of anthropoids - then at the very least it is hard to see how we can achieve the necessary confidence and resolution to follow the path of goodness; and at worst the very idea that some lives can be more meaningful than others begins to seem a fantasy (Cottingham 2003, 72).

Paralleling the distinction between intrinsic value (goodness for its own sake) and extrinsic value (goodness as a means), I read Cottingham as making two claims above: (1) that the existence of God and a soul partially constitute intrinsic meaning, i.e., that no life could be meaningful if neither existed; and (2) that acting as though they exist 
is extrinsically meaningful, that is, cultivates the tenacity needed for a given person to act in accordance with God-based moral norms and thereby obtain intrinsic meaning. About a third of Cottingham's book eloquently defends this second claim, articulating both the sort of religious way of life he believes is best able to promote meaning and the reasons for living religiously in the absence of compelling evidence that a supernatural order exists.

Let us first see how to question Cottingham's arguments with respect to the claim that intrinsic meaning in life is partially constituted by the existence of God and a soul. Recall that one argument is that since meaning in life requires action according to moral norms that apply to all rational beings, and since only God could ground such norms, God is necessary for meaning in life. One can reasonably doubt both premises. First, there are of course notorious problems with the divine command theory of morality, problems that Cottingham acknowledges. He explicitly contends that moral rules must be backed up by reasons, which reasons are not merely a function of God's will. The question, then, is: how else could God constitute moral norms if not by commands, preferences or other arbitrary features? Cottingham does not try to answer the question here, and, in the absence of an answer, one might think that a Rossian nonnaturalism or a Kantian rationalism would best underwrite a strictly universal morality. Cottingham does argue for supernaturalism relative to competitors in later work, ${ }^{9}$ but, for the sake of focus on the present text, I move on to a second objection.

One can also question the premise that a strictly universal morality is necessary for meaning in life. While some such as Richard Taylor seem willing to deny that any morality at all is necessary for meaning, ${ }^{10}$ I do not pursue that line here. I instead discuss whether a morality applicable to all human persons, but not necessarily persons as such, might not suffice. Suppose that there were a system of moral rules applicable to humans instructing them to help each other, but that this system applied to no other group of agents. My intuition is that acting according to such a merely comparatively universal system would confer meaning on our lives.

\footnotetext{
${ }^{9}$ Cottingham 2005.

${ }^{10}$ Taylor 1987.
} 
Furthermore, this intuition is buttressed in light of an analogy with other goods that are reasonably taken to constitute meaning. Making a great advance in science and creating a great artwork are plausibly deemed to be ways to confer significance on one's life. But the laws of beauty, if there even are any, are applicable to at most our species; it is unlikely such laws would apply to agents with different sensibilities. In addition, scientific laws construed in realist terms are probably valid for at most us as a species, with no compelling reason to think that other species must conceptualise the world in fundamentally the same way. If art (the beautiful) and science (the true) are at most species-specific in their scope and yet are able to confer meaning on our lives, then, by analogy, it is plausible to think that morality (the good) is, too. And a species-specific morality need not be grounded by God; it could plausibly obtain by virtue of a common evolutionary history, ${ }^{11}$ a common reference to a certain natural kind with the term "moral, ${ }^{12}$ or a common ability to detect something akin to a secondary property. ${ }^{13}$

Let us now turn to Cottingham's second argument for thinking that God and a soul in part make up (intrinsic) meaning in life. It says that since success is necessary for meaning, and since God and a soul are necessary for success, God and a soul are necessary for meaning. First off, one might doubt that the existence of God is needed to realise our ends. It is conceivable that an impersonal force, rather than a personal being, could arrange the world so that our goals are ultimately achieved. For instance, if our goals are deserved, then some form of Karma would do the trick.

Now, since success is a relative rarity in this world, a life in another world is needed by which either God or Karma could help us along. Cottingham's present rationale might therefore seem to support at least the claim that a soul (if not God) is necessary for meaning in life.

However, it is not clear that even this weaker entailment obtains. Having the prospect of an afterlife, whether immortal or not, is distinct from having a soul. If one is essentially a chain of memories or configuration of other mental states, then these could conceivably be transferred from one's present body to another one after its death. There is no clear reason why one requires a soul in order to outlive

\footnotetext{
${ }^{11}$ E.g., Ruse 2002.

${ }^{12}$ E.g., Brink 1989.

${ }^{13}$ E.g., McDowell 1985.
} 
one's present body. Hence, even if we must exist after the death of our (present) bodies in order for our ends to be fulfilled to such a degree as to obtain meaning, it does not follow that we must have a soul.

A second objection to the present argument is that success is not necessary for meaning, only the right sort of effort is. Oddly, this is something that Cottingham himself in the end comes close to admitting. He advocates 'a certain mindset which will not judge the value of sticking to the side of goodness by reference to its success or failure measured in terms of outcome, but which generates the courage to endure, irradiated by hope' $(2003,74)$ and elsewhere he speaks of 'turning away from evaluations based solely on external success' (2003, 85). I worry that such pronouncements undercut one of Cottingham's major rationales for thinking that God and a soul are necessary for meaning in life, namely, that 'the hard truth is that our assessment of the value of a project — and this includes the sincere pursuit of morally worthy goods - is at least partly success-oriented: we require it not just to be undertaken in the right spirit, but to achieve something' $(2003,66)$, which Cottingham maintains requires a supernatural realm.

The most natural ways to reconcile the apparent tension in the text, I think, would be to say either that success is merely a matter of cultivating the right sorts of internal dispositions, habits and will, apart from what these conditions might bring about in the external world, or that success includes an external element but that not much of it is necessary for meaning. The deep problem with these straightforward ways of resolving the tension, however, is that either sort of success (internal or minimal external) can be routinely achieved without the existence of God, a soul, or any sort of afterlife.

So far, I have questioned what I take to be Cottingham's two central arguments for thinking that a relationship with a spiritual world is at least part of what it essentially is to live a meaningful life. The objections share a common feature: they both argue that aspects of a purely natural world could do the job for which God and a soul are thought to be needed. Both an objective morality and a sufficient realisation of moral ends seem possible in a merely physical world. In light of this problem, perhaps the supernaturalist about meaning should seek to ground meaning in spiritual qualities that most clearly cannot be manifest in the natural world, qualities such as atemporality, immutability, simplicity, and indivisibility. This strategy is rela- 
tively unexplored in the English speaking philosophical literature, but worth development. ${ }^{14}$

Now I turn to Cottingham's argument for the claim that, in order to have the resolution required to carry out challenging moral projects and thereby obtain intrinsic meaning, we must act as though God and a soul exist and ideally believe in them as well. I suspect that this claim about extrinsic meaning depends on those about intrinsic meaning that were questioned above. If it is correct that neither moral rules nor moral success depend on the existence of God or a soul, then a religious lifestyle is unnecessary for moral motivation. Again, if God does not constitute moral rules the following of which confers meaning on life, and if neither God nor a soul is necessary for moral achievement of the sort that confers meaning, then a person need not believe in the existence of a supernatural realm, or act as though it exists, in order to be sufficiently determined in the face of moral difficulty. At most, she would have to be positively oriented toward the relevant natural properties that make moral norms and ends conforming to them possible.

In this short article, I of course have come to no conclusion about how to resolve the dispute between naturalism and supernaturalism with respect to meaning in life. My goal has instead been to extract key arguments relevant to this debate from two books by powerful analytic thinkers, Kurt Baier and John Cottingham. I have worked to show that their arguments are worth serious consideration, to indicate some potential weaknesses in them, and to suggest some other argumentative strategies that those interested in this fascinating but underexplored topic might pursue elsewhere in more depth. ${ }^{15}$

$$
\begin{array}{r}
\text { Thaddeus Metz } \\
\text { Dept. of Philosophy } \\
\text { University of the Witwatersrand } \\
\text { Private Bag 3, WITS 2050, South Africa } \\
\text { metzt@social.wits.ac.za }
\end{array}
$$

\footnotetext{
${ }^{14}$ For more on this strategy, see Metz 2000.

${ }^{15}$ I would like to thank Annette Baier, Kurt Baier and John Cottingham for reading a draft of this article. I would also like to thank the University of Missouri Research Board for funding the research leave during which I wrote it.
} 


\section{References}

Baier, Kurt. 1957. The Meaning of Life. Reprinted in E. D. Klemke (ed.), The Meaning of Life, $2^{\text {nd }}$ ed. New York: Oxford University Press, 2000.

Baier, Kurt. 1997. Problems of Life and Death: A Humanist Perspective. Amherst, NY: Prometheus Books.

Brink, David. 1989. Moral Realism and the Foundations of Ethics. New York: Cambridge University Press.

Cottingham, John. 2003. On the Meaning of Life. New York: Routledge.

Cottingham, John. 2005. The Spiritual Dimension: Religion, Philosophy and Human Value. Cambridge: Cambridge University Press.

Flew, Anthony. 1966. God and Philosophy. New York: Harcourt, Brace, \& World, Inc.

Gewirth, Alan. 1998. Self-Fulfillment. Princeton: Princeton University Press, Chapter 5.

McDowell, John. 1985. Values and Secondary Qualities. In Ted Honderich (ed.), Morality and Objectivity. London: Routledge and Kegan Paul.

Metz, Thaddeus. 2000. Could God's Purpose Be the Source of Life's Meaning? Religious Studies 36: 293-313.

Metz, Thaddeus. 2001. The Concept of a Meaningful Life. American Philosophical Quarterly 38: 137-153.

Metz, Thaddeus. 2002. Recent Work on the Meaning of Life. Ethics 112: 781-814.

Metz, Thaddeus. 2003. Utilitarianism and the Meaning of Life. Utilitas 15: 50-70.

Nozick, Robert. 1981. Philosophical Explanations. Cambridge, MA: Harvard University Press, Chapter 6.

Nussbaum, Martha. 1989. Mortal Immortals: Lucretius on Death and the Voice of Nature. Philosophy and Phenomenological Research 50: 303-351.

Ruse, Michael. 2002. Evolution and Ethics (Rev. Ed.). In Louis Pojman (ed.), Ethical Theory, $4^{\text {th }}$ ed. Belmont, CA: Wadsworth Publishers.

Taylor, Richard. 1987. Time and Life's Meaning. The Review of Metaphysics 40: 675-686. 